\title{
Lessons learnt from the introduction of the contraceptive implant in South Africa
}

\author{
M Pleaner, ${ }^{1}$ MEd; C Morroni, ${ }^{1,2,3,4}$ MB ChB, DFSRH, DTM\&H, MPH, MSc, PhD; J Smit, ${ }^{5}$ BPharm, MSc, PhD; \\ N Lince-Deroche, ${ }^{6}$ MIA, MPH, PhD; M F Chersich, ${ }^{1}$ MB BCh, PhD; S Mullick, ${ }^{1}$ MB ChB, MSc, MPH, PhD; D Pillay, ${ }^{1} \mathrm{MPH}$; \\ M Makua, ${ }^{7}$ DLitt et Phil, MTech; H Rees, ${ }^{1}$ MB BChir, MA (Cantab), MRCGP, DCH, DRCOG
}

\author{
${ }^{1}$ Wits Reproductive Health and HIV Institute, Faculty of Health Sciences, University of the Witwatersrand, Johannesburg, South Africa \\ ${ }^{2}$ Women's Health Research Unit, School of Public Health and Family Medicine, Faculty of Health Sciences, University of Cape Town, South Africa \\ ${ }^{3}$ EGA Institute for Women's Health and Institute for Global Health, University College London, UK \\ ${ }^{4}$ The Botswana-UPenn Partnership, Gaborone, Botswana \\ ${ }^{5}$ Maternal Adolescent and Child Health (MatCH) Research Unit, Department of Obstetrics and Gynaecology, Faculty of Health Sciences, \\ University of the Witwatersrand, Durban, KwaZulu-Natal; and School of Health Sciences, University of KwaZulu-Natal, Durban, South Africa \\ ${ }^{6}$ Health Economics and Epidemiology Research Office, Department of Internal Medicine, School of Clinical Medicine, Faculty of Health Sciences, \\ University of the Witwatersrand, Johannesburg, South Africa \\ ${ }^{7}$ National Department of Health, Pretoria, South Africa
}

Corresponding author: M Pleaner (mpleaner@mweb.co.za)

\begin{abstract}
In 2014, South Africa (SA) introduced the subdermal contraceptive implant with the aim of expanding the contraceptive method mix and availability of long-acting reversible methods in the public sector. Three years on, concerns have been raised about the decline in uptake, early implant removals and challenges in service delivery. This article explores the lessons learnt from the introduction of contraceptive technologies elsewhere and applies these to the SA context. Drawing on the World Health Organization's conceptual framework for the introduction of new contraceptive methods, and subsequent literature on the topic, lessons are classified into six cross-cutting themes. Recommendations highlight the need for SA to review and explore strategies to strengthen current implant services, including the provision of improved provider training aimed at sensitive, client-centred approaches; increased community engagement; and improved systems for programmatic monitoring and evaluation. With implementation of these recommendations, worrying trends in the provision of implants could be reversed.
\end{abstract}

S Afr Med J 2017;107(11):933-938. DOI:10.7196/SAMJ.2017.v107i11.12805

This article explores the complexities of introducing new contraceptive technologies and applies these to the initiation of the subdermal contraceptive implant (implant) in the South African (SA) context. Using the World Health Organization (WHO)'s conceptual framework $^{[1,2]}$ and other emerging literature, lessons are identified and key recommendations proposed.

Over the past decade there have been concerted efforts to promote long-acting reversible contraceptive (LARC) methods in sub-Saharan Africa, especially the implant and the copper intrauterine device (IUD). ${ }^{[3,4]}$ These methods have high continuation rates compared with other methods and very high effectiveness ( $<1$ unintended pregnancy per 100 women-years). ${ }^{[5]}$ It is estimated that almost 2 million unintended pregnancies could be averted over 5 years if only $20 \%$ of women in sub-Saharan Africa, currently using shorter-acting methods (oral contraceptives or injectables), switched to the implant. ${ }^{[6]}$ In this region, the contraceptive method mix has long been dominated by these shorter-acting methods, which, when used correctly, are highly effective and acceptable to women. However, these methods are also associated with significant rates of discontinuation, incorrect use, poor adherence and consequent unintended pregnancy. ${ }^{[7]}$ Similarly, SA's most commonly used contraceptive methods are the injectables, ${ }^{\left[{ }^{8]}\right.}$ depot-medroxyprogesterone acetate (DMPA) and norethisterone enanthate (NET-EN), which account for half of contraceptive use nationally. ${ }^{[9,10]}$

The implant is registered for use in more than 100 countries worldwide ${ }^{[11]}$ including many in sub-Saharan Africa, where use has increased rapidly over the past decade ${ }^{[12,13]}$ In 5 years, uptake doubled in Malawi, quadrupled in Tanzania, and rose more than 15-fold in Rwanda and Ethiopia. ${ }^{[12,14,15]}$ In Zimbabwe, for example, implant use increased from $<1 \%$ in 1994 to $10 \%$ by $2015 .^{[16]}$ In 2014 , SA introduced the implant - somewhat later than other countries in the region - in an effort to expand its method mix and especially to increase access to LARCs, which have been given centre place in the country's contraception policy. ${ }^{[17,18]}$ Aside from the effectiveness of LARC methods and the benefits of increasing method choice, ${ }^{[19,20]}$ the possible links between injectables (particularly DMPA) and risk of HIV acquisition provided an impetus for the introduction of alternative methods in SA. ${ }^{[18,21,22]}$

The launch of the implant in SA was accompanied by much excitement and anticipation - it was the first new method introduced in the public sector in almost 20 years. Implant services were described as 'the biggest family planning programme SA has ever seen, ${ }^{[23]}$ with $\geq 6000$ healthcare providers trained with regard to implant provision, with a focus on insertion. Both the 5-year, two-rod levonorgestrel implant (Jadelle) and the 3-year, single-rod etonogestrel implant (Implanon NXT) were registered with the SA Medicines Control Council for use, but only Implanon NXT was made available in public health clinics as part of the national contraception programme. Estimates of implant uptake in the year after launch ranged from 176000 , based on data reported to the District Health Information System (DHIS), to as high as 900 000, according to the Department of Health. ${ }^{[2,25]}$ Data from the subsequent years, however, showed an almost $50 \%$ decrease in insertion numbers year on year. ${ }^{[26]}$ The number of insertions dipped considerably across all districts that reported these data 
(Table 1, Fig. 1). The Demographic and Health Survey (2016) estimated implant use at $8 \%$ for married and sexually active unmarried women. ${ }^{[10]}$ Actual numbers of removals are not known, because these were not initially systematically recorded. However, some reports in the media suggested that early removals were common and that women faced difficulties in getting implants removed because of healthcare-provider resistance to removal. ${ }^{[27,28]}$ Therefore, while the introduction of the implant heralded an important step towards the strengthening of SA's contraception programme, and brings the country on par with its regional counterparts in terms of wider method choice, SA's implant programme is facing several challenges.

Many of these challenges are common to the introduction of new contraceptive technologies elsewhere. On occasion, the roll-out of a new contraceptive method has been undermined by adverse events and negative user experiences related to inadequate quality of care, which even if uncommon, have resulted in adverse publicity, rumours and misperceptions. It is, therefore, timely and critical to reflect on lessons learnt from the early period of implant avail-

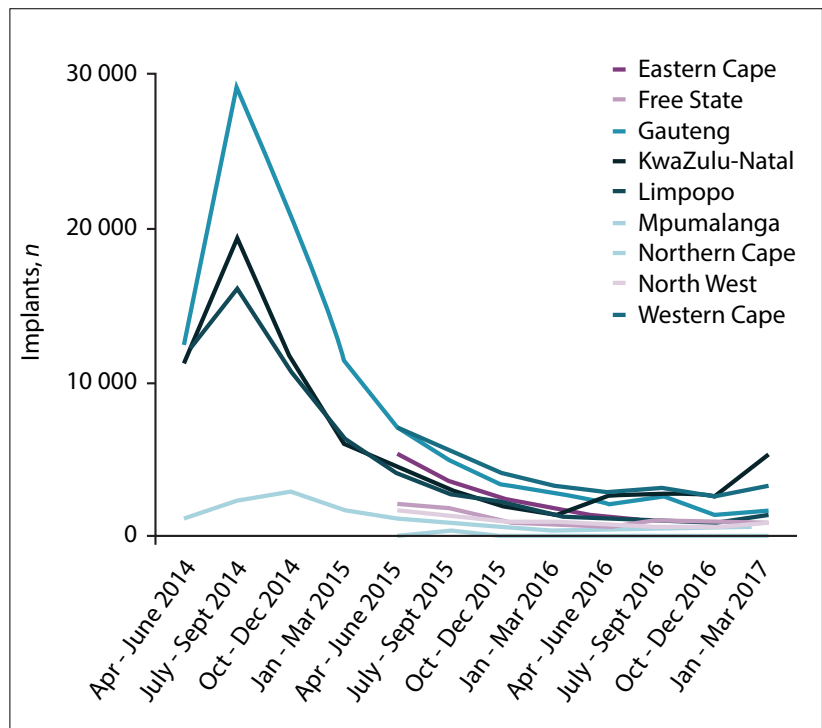

Fig. 1. Implant insertions in SA by province (April 2014 - March 2017). ${ }^{[26]}$ (No data are available for the Eastern Cape, the Free State, Mpumalanga, North West and the Western Cape before April - June 2015.) ability in SA, based mainly on the experiences and insights of the authors, all of whom are closely involved in the SA contraception programme. These lessons are placed in the context of similar experiences of contraceptive introduction elsewhere. We classify these findings into six thematic areas, drawing on a WHO conceptual framework for the introduction of a contraceptive method, ${ }^{[1,2]}$ as well as subsequent literature on the topic. ${ }^{[29-33]}$ We then propose key steps that could reinforce and reconfigure the implant programme in SA.

\section{Lessons learnt - six thematic areas 1. Learn from the 'boom-and-bust' phenomenon in family planning}

The term 'boom-and-bust' in family planning describes the phenomenon in which there is an initial boom in the use of a new contraceptive technology, coupled with excitement and optimism, followed by a rapid downturn due to unmet expectations and disappointment - the 'failed promise of the contraception revolution.' ${ }^{[33]}$ Several contraceptive methods have had a particularly turbulent history, as summarised in Box 1. Concerns have been raised about the potential for the implant to follow a similar trajectory if lessons from the past are not heeded. ${ }^{[15]}$

Importantly, the boom-and-bust phenomenon in family planning can have far-reaching, long-term, negative consequences, creating a climate of mistrust and lack of confidence in a method, or even in family planning services, more broadly. These effects may be experienced many years afterwards - for both providers and consumers - and may result in withdrawal of the method. ${ }^{[2]}$

The boom-and-bust concept explicitly acknowledges the importance of closely monitoring the introduction of a new method, and then swiftly recognising and addressing the causes of any downward turn in uptake or acceptability more generally. Accurate data on uptake, pharmacovigilance, and levels of discontinuation or removal and reasons thereof are especially important.

\section{Promote informed choice}

In the enthusiasm of introducing a new, promising contraceptive method, there may be a tendency to promote that method over others, ${ }^{[2,7,37]}$ both programmatically and at the level of individual provider-client interactions. This bias, which may be overt or subtle, may result in the provision of incomplete information and counselling, the over-selling

Table 1. Contraception methods dispensed, 2013/2014 - 2015/2016 ${ }^{[26]}$

\begin{tabular}{|c|c|c|c|c|c|c|c|}
\hline \multirow[b]{2}{*}{$\begin{array}{l}\text { Type of contraceptive } \\
\text { dispensed }\end{array}$} & \multicolumn{2}{|c|}{$2013 / 2014$} & \multicolumn{2}{|c|}{$2014 / 2015$} & \multicolumn{2}{|c|}{$2015 / 2016$} & \multirow{2}{*}{$\begin{array}{l}\text { Change 2014/ } \\
2015 \text { - 2015/ } \\
2016, \%\end{array}$} \\
\hline & $n$ & $\begin{array}{l}\text { Contraceptive } \\
\text { years dispensed }\end{array}$ & $n$ & $\begin{array}{l}\text { Contraceptive } \\
\text { years dispensed }\end{array}$ & $n$ & $\begin{array}{l}\text { Contraceptive } \\
\text { years dispensed }\end{array}$ & \\
\hline Female condoms & 13254328 & 66271 & 21099517 & 105497 & 27005805 & 135029 & 28 \\
\hline IUD inserted & 41817 & 167268 & 39168 & 156672 & 15150 & 60600 & -61.3 \\
\hline Male condoms & 506431299 & 2532156 & 712387234 & 3561936 & 839874751 & 4199373 & 17.9 \\
\hline Medroxyprogesterone & 5762721 & 1440680 & 5510430 & 1377607 & 5578228 & 1394557 & 1.2 \\
\hline $\begin{array}{l}\text { Norethisterone } \\
\text { enanthate }\end{array}$ & 4277194 & 712865 & 3834005 & 639000 & 3676445 & 621740 & -4.1 \\
\hline Oral pill cycles & 3815539 & 293503 & 3560421 & 273878 & 3591382 & 276260 & 0.9 \\
\hline Sterilisation female & 31551 & 631020 & 32074 & 641480 & 33134 & 662681 & 3.3 \\
\hline Sterilisation male & 1120 & 11200 & 877 & 8770 & 772 & 7720 & -12 \\
\hline $\begin{array}{l}\text { Subdermal implant } \\
\text { inserted }\end{array}$ & - & - & 175948 & 527844 & $87189^{*}$ & 261567 & -50.4 \\
\hline Total & - & 5854963 & - & 7292684 & - & 7619527 & 4.4 \\
\hline
\end{tabular}




\section{Box 1. Boom-and-bust of contraception methods}

- The Lippes Loop IUD, introduced in 1960, was aggressively promoted in India, with 'loop squads' and cash incentives, and $>2$ million insertions were done between 1965 and 1967. ${ }^{[3]}$ Very high levels of early removal have been mostly attributed to over-zealous persuasion of women to use the IUD, with little attention to method choice, counselling about method disadvantages, and possible side-effects, e.g. bleeding and cramping. The India Family Planning Programme also failed to address widespread rumours, misconceptions and cultural issues relating to the device. ${ }^{[34]}$ The shortcoming of the Lippes Loop introduction negatively impacted IUD use in India for many years. ${ }^{[1,35]}$

- The Dalkon Shield IUD, which was introduced as a 'safe' alternative to the oral contraceptive pill in the 1970s, was the target of legal action in the USA, and the subject of extensive negative publicity, and was ultimately removed from the market. While removal of the device was justified, as it was determined that a structural flaw in the device caused septic abortions and pelvic infections, this controversy contributed to negative perceptions about safer, new-generation IUDs, and is partially responsible for the lingering, even though now disproven, concerns about IUDs causing pelvic inflammatory disease. ${ }^{[36]}$ This experience highlights the need to invest effort in debunking misconceptions and providing correct information.

- Another example is provided by Norplant. This six-rod subdermal progestin-only implant, was seen as a major breakthrough in contraceptive technology when it was introduced in several countries, including the USA, UK and Indonesia, in the 1990s. Accusations of failure of the manufacturer to disclose side-effects led to litigation in the USA. Although the litigation was ultimately unsuccessful, it was accompanied by negative publicity and, along with problems in other countries, contributed to Norplant's withdrawal from the market in 2006. ${ }^{[29]}$ Other problems with Norplant related to quality of care, including mass insertions, called 'safaris' in Indonesia, leading to perceptions of client coercion; ${ }^{[30]}$ inadequate provider training and lack of competency in insertion and removal; accusations of healthcareworker resistance to removal; and poor-quality counselling. ${ }^{[31]}$

of the benefit of the new method, a lack of acknowledgment that each contraceptive method comes with advantages and disadvantages, and that the importance of these differ from person to person. Within the early stages of the implant programme in SA, concerns arose that contraceptive users were not being given an adequate choice of methods, with the implant being strongly promoted as the first-line method, and with insufficient counselling about possible side-effects or alternative contraceptive options.

\section{Avoid over-emphasis of method technology and technological advantages}

A focus on technological advantages of the implant, e.g. its longterm action, high efficacy and cost-effectiveness, may overshadow a woman's personalised experience of the method, especially the impact and tolerability of side-effects. Most importantly, a preoccupation with the long-acting dimensions of the LARCs can result in preeminence being given to the continuation rate as the indicator of success and acceptability. If that occurs, then early removal is seen as problematic and even as wasteful, and may generate resistance among healthcare providers to performing early removals. ${ }^{[31]}$

In SA, an over-emphasis on the notion of ' 3 years of use' perhaps has meant that the programme did not adequately anticipate and prepare for early removals, as these were viewed as signalling a failure of the programme rather than merely a reflection of the varying needs of women over time, which is to be expected and should be planned for. Implant removals are common across all settings. For example, about a quarter of women discontinued within the first year of use in studies in the Netherlands, ${ }^{[38]}$ the UK and Australia, ${ }^{[39,40]}$ as well as other settings. ${ }^{[14,15]}$ Also, the reality of early removal levels may not always match perceptions, e.g. in Ethiopia concerns arose about early removals, but an evaluation showed that only $\sim 2 \%$ of implant users had discontinued the method by 6 months. ${ }^{[41]}$

It is important to keep implant removals in perspective - because the implant requires healthcare-provider intervention for removal, providers generally hear of and see women who are dissatisfied with the method and/or who request removals, and not the many 'silent' women who are satisfied with the method and only return to the clinic after 3 years. Furthermore, healthcare providers are generally not accustomed to having to actively manage discontinuation of contraceptives. Women discontinue pills or injections on their own, contributing to the perception that there is a higher rate of implant discontinuation compared with other methods.

Conceptually, thinking and language need to move away from the notion that the implant is designed to be used for a certain number of years, to the more nuanced message that it can be used for a number of years if women choose to do so. ${ }^{[1,31,42]}$ Key to improving implant provision is understanding the reasons for early removals, e.g. are these due to inadequate counselling; dissatisfaction with the method; lack of support while using the method, including assistance in dealing with side-effects; or women no longer being sexually active or wanting to become pregnant?

\section{Focus on quality standards and overall access, rather than targets for an individual method}

Internationally, it is common practice to make contraceptive programmes heavily target driven, and although this is often well intentioned, it may compromise quality of care. ${ }^{[15]}$ An example is target setting for training, which occurred in SA, with a focus on numbers of providers trained, rather than on quality of training and documenting provider proficiency outcomes. The number of devices inserted is also often target driven, and can occur at the expense of oversight of the quality of care provided ${ }^{[42,43]}$ While there are merits to setting targets, e.g. around overall contraceptive prevalence in a country, indicators need to centre around access, which includes dimensions such as quality of services and client satisfaction, rather than merely uptake.

\section{Adoption of innovative, acceptable and comprehen- sive service-delivery models}

Innovative models of service delivery warrant consideration, drawing on experiences from other settings. For example, the use of dedicated, specially trained providers might be more appropriate where new clinical skills, such as implant removals, are difficult to roll out to large numbers of providers. In 2008 - 2009, Zambia trained 18 retired midwives and deployed them to high-volume, public-sector facilities, solely for the provision of LARC services over 14 months, which showed a marked increase in uptake over a short period of time. ${ }^{[14,44]}$

A key challenge for implant service delivery is getting the balance right in relation to training on insertions and removals. The pattern of introducing implants and focusing training on insertions and not 
on removals, has repeated itself across countries. ${ }^{[14,19]}$ This approach is based on the assumption that there would be a window of several years in which to do this training. Also, practically, it is difficult for healthcare providers to learn how to perform removals at the onset of a programme, when few insertions have been made. Often, there is intent to do training on removals, but once the implant is introduced the momentum for training dissipates. Clearly, access to quality removal services from the onset of an implant programme is essential. Many countries have underestimated the number of women who would request removals before 3 years. ${ }^{[1,15]}$ Failure to provide accessible removal services is an infringement of women's rights, and may impact negatively on the community's perception of the implant.

Expanding the choice of contraceptive methods does not necessarily result in increased utilisation if constraints in the health system and the needs of the end user are not taken into account. ${ }^{[2,31]} \mathrm{A}$ holistic perspective is called for, tailored to the social, cultural, and personal norms and values that influence patterns of use in a particular context. Such a perspective explicitly acknowledges that the implant is most often used by healthy women, who may not be willing to accept sideeffects, ${ }^{[37,45]}$ many of which are genuinely uncomfortable..$^{[2,14,45]}$

The needs of women also change with age. Of note, adolescents have specific considerations, which are best met within the context of youth-sensitive services. ${ }^{[46-48]}$ Little has been done to promote the implant among SA adolescents, with a commonly held perception that the method is more suitable for adults. Several studies, however, show that the implant is highly acceptable to young women, ${ }^{[49,50]}$ with continuation rates of $\sim 80 \%$ after 12 months, ${ }^{[51]}$ including in studies in sub-Saharan Africa. ${ }^{[52]}$

Lastly, the importance of demand creation, community engagement, sensitisation and addressing of concerns as they relate to a woman's life and context requires emphasis. ${ }^{[33]}$ This involves generating a dialogue and structured engagement with programme planners, health workers, communities and end users to identify and address barriers..$^{[1,32,53]}$ Non-governmental organisations, researchers and technical assistance agencies could all make an important contribution to such efforts.

\section{Ensure a rights-based approach}

The abovementioned lessons draw together important strands, which locate the promotion of the implant within the context of sexual and reproductive health and rights. ${ }^{[13,54-57]} \mathrm{A}$ rights-based approach is especially important given that, historically, family planning programmes in SA have been associated with coercion. ${ }^{[58,59]}$

Most importantly, services must take into account the gamut of social, cultural and relational factors that influence contraceptive uptake and continued use. Each new method carries a set of trade-offs for healthcare systems, providers and end users that will influence acceptability and continued use. ${ }^{[2]}$ Therefore, optionsbased, rather than directive counselling, is required, so that the implant is not recommended above other methods. Effectiveness is only one of many criteria that determine the optimum method for a woman at a particular point in time, and other factors may guide her choice, including how frequently she has sex, her partner's involvement, her fertility desires, and cultural or personal issues relating to side-effects. Sensitivity and attention to these dimensions ensure that clients are informed and have agency regarding method selection, and continuing or discontinuing use.

\section{Recommendations}

Based on the lessons described above, we propose the following priority recommendations to support SA's implant programme:

\section{Capacity building for healthcare providers}

- The expanded provision of new and refresher training courses for healthcare providers, which cover technical skills around insertion and removal, informed decision-making and choice for women, pre-insertion counselling, especially around side-effects, and longterm support and management of side-effects.

- Capacity building needs to strengthen provider confidence and competence in insertions and removals, recognising that this requires an investment in quality training, effective supervision, structured mentorship and accessible on-site support.

- Training and support need to include more nuanced counselling, which should address issues such as changes in bleeding patterns and how this may affect women's lives, e.g. the cost of sanitary wear and sexual relationships. Reassurance and competent management of side-effects play a major role in determining whether a woman chooses to continue the method.

- A skills and human resource assessment needs to be done, especially in relation to implant removals, and measures should be put in place to address gaps.

- Training needs to focus on the most recent WHO medical eligibility criteria guidance for the implant, in particular the suitability of implants for women of all ages, including adolescents, and highlight potential advantages of the method for this group.

\section{Clear communication to healthcare providers and end users regarding drug interactions}

- Clear communication needs to be provided for both healthcare providers and end users where drug interactions might be a potential problem, including for those on treatment for tuberculosis (TB), HIV or epilepsy. ${ }^{[60,61]}$ In the presence of ambiguity, healthcare providers understandably err on the side of caution, either not offering implants to potentially eligible women or unnecessarily encouraging removal.

\section{Data collection and monitoring systems}

- Address data gaps in recording of uptake, removals and pharmacovigilance, including use of the implant in women with medical conditions such as epilepsy, HIV and TB.

- Disaggregate implant data by age (especially to identify use among adolescents and young women) and by specific groups of women, such as postpartum and post-abortion patients. This can then be used to identify gaps in provision, training, quality of care, and factors influencing uptake and continuation.

\section{Increase demand}

- Adopt innovative service-delivery models, which could include 're-introducing' the implant (and other LARC methods, such as the IUD) in selected districts; engage with communities in terms of myths, misconceptions and women's experiences with the method; and debrief healthcare providers about their experiences with the method and their concerns.

\section{Assess the feasibility of further expanding the contraceptives available in the public sector}

- Contraceptive use may be increased by expanding the range of methods available to accommodate different needs. ${ }^{[20]}$ The SA contraception policy recommended a 5-yearly review (2012 - 2017). ${ }^{[17,62]}$ This is now imminent and presents a window of opportunity to review the guidelines. More specifically, based on the concerns raised in this article, the review should consider uptake of and barriers to the use of all methods. With the emergence of new data, further consideration should be given to different contraceptives among women at risk of HIV and those 
infected with HIV or TB, including guidance on contraceptive prescribing and drug interactions.

\section{Conclusion}

Problems and challenges encountered during the introduction phase of the contraceptive implant in SA are not unique, and mirror experiences elsewhere. Lessons learnt elsewhere provide valuable insights about the health-system elements required to support service provision and demand creation, as well as ensuring that these take place within a rights-based framework. It is critical to heed these lessons, identify and analyse problems and deal with them effectively to ensure success of implant introduction.

Real or perceived concerns about new methods, such as the implant, may discredit the use of methods by current and potential users, communities and healthcare providers. It is imperative that the potential contribution of the implant to women's health in SA is not undermined by unsubstantiated negative publicity and misconceptions, or by the unwarranted importance assigned to removal rates not supported by data.

Addressing the skewed contraceptive method mix in SA and promoting a greater choice of methods, including the implant, require nuanced provider training and sensitivity, novel health-system support, intensive community engagement, consumer awareness, and systems for programmatic monitoring, evaluation and quality improvement. While this article specifically addresses issues relating to implants, many of these reflections may apply to the strengthening of other LARC methods, such as the IUD, and indeed, the contraceptive programme as a whole.

Acknowledgements. A word of appreciation to Dr Manala Makua for her feedback and guidance, and to the collective contribution of the authors for the evolution and completion of this article. A special word of thanks to Candy Day (Health Systems Trust) for providing updated DHIS data, and Alida Gertz (Afya Bora Global Health Fellow, The Botswana-UPenn Partnership) for assistance with designing Fig. 1.

Author contributions. MP: conceptualised the article and worked on it to completion; CM, JS, NL-D: reviewed and assisted with the development of the initial drafts; MFC, HR, SM, DP, MM: edited and revised subsequent drafts; and CM, HR, MFC: read and approved the final manuscript.

\section{Funding. None.}

Conflicts of interest. None.

1. World Health Organization. Expanding Family Planning Options: Contraceptive Introduction Reconsidered: A Review and Conceptual Framework. Geneva: WHO, 1994.

2. Simmons R, Hall P, Díaz J, Díaz M, Fajans P, Satia J. The strategic approach to contraceptive introduction. Stud Fam Plann 1997;28(2):79-94. https://doi.org/10.2307/2138111

3. Ngo TD, Nuccio O, Pereira SK, Footman K RK. Evaluating a LARC expansion program in 14 subSaharan African countries: A service delivery model for meeting FP2020 goals. Matern Child Health J 2016;21(9):1734-1743. https://doi.org/10.1007/s10995-016-2014-0

4. Staveteig S, Mallick L. Uptake and discontinuation of longacting reversible contraceptives (LARCs) in low-income countries. DHS Anal Stud 2015;(54).

5. Trussell J. Contraceptive efficacy. In: Hatcher RA, Trussell J, Nelson AL, Cates W, Kowal DPM, eds. Contraceptive Techology. 20th rev. ed. New York: Ardent Media, 2011.

6. Hubacher D, Mavranezouli I, McGinn E. Unintended pregnancy in sub-Saharan Africa: Magnitude of the problem and potential role of contraceptive implants to alleviate it. Contraception 2008;78(1):73-78 https://doi.org/10.1016/j.contraception.2008.03.002

7. Bertrand JT, Sullivan TM, Knowles EA, Zeeshan MF, Shelton JD. Contraceptive method skew and shifts in method mix in low- and middle-income countries. Int Perspect Sex Reprod Health 2014;40(3):144-146. https://doi.org/10.1363/4014414

8. Baumgartner JN, Morroni C, Mlobeli RD, et al. Timelines of contraceptive reinjections in South Africa and its relation to unintentional discontinuation. Int Fam Plan Perspect 2007;33(2):66-74. https://doi. org/10.1363/ifpp.33.066.07

9. Chersich MF, Wabiri N, Risher K, et al. Contraception coverage and methods used among women in South Africa: A national household survey. S Afr Med J 2017;107(4):307-314. https://doi.org/10.7196/ SAMJ.2017.v107i4.12141

10. Department of Health, Statistics South Africa, South African Medical Research Council. South African Demographic and Health Survey 2016: Key Indicators. Pretoria: SSA, 2017.

11. Lince-Deroche N, Pleaner M, Harries J, et al. Achieving universal access to sexual and reproductive health services: The potential and pitfalls for contraceptive services in South Africa. In: Padarath A, King J, Mackie E, Casciola J, eds. South African Health Review 2016. Durban: Health Systems Trust, 2016. 12. United States Agency for International Development. Three Successful Sub-Saharan Africa Family
Planning Programs: Lessons for Meeting the MDGs. Washington DC: USAID, 2012:1-31.
13. Hardee K, Harris S, Rodriguez M, et al. Achieving the goal of the London summit on family planning by adhering to voluntary, rights-based family planning: What can we learn from past experiences with coercion? Int Perspect Sex Reprod Heal 2014;40(4):206-214. https://doi. org/10.1363/4020614

14. Jacobstein R, Stanley H. Contraceptive implants: Providing better choice to meet growing family planning demand. Glob Health Sci Pract 2013;1(1):11-17. https://doi.org/10.9745/ghspd-12-00003

15. Hubacher D, Dorflinger L. Avoiding controversy in international provision of subdermal contraceptive implants. Contraception 2012;85(5):432-433. https://doi.org/10.1016/j.contraception.2011.11.018

16. Zimbabwe National Statistics Agency and ICF International. Zimbabwe Demographic and Health Survey 2015: Final Report. Rockville, Md, USA: ZIMSTAT and ICFI, 2016.

17. Department of Health. National Contraception and Fertility Planning Policy and Service Delivery Guidelines. Pretoria: DoH, 2012.

18. Department of Health. National Contraception Clinical Guidelines. Pretoria: DoH, 2012.

9. Hubacher D, Dorflinger L. Avoiding controversy in international provision of subdermal contraceptive implants. Contraception 2012;85(5):432-433. https://doi.org/10.1016/j.contraception.2011.11.018

20. Ross J, Stover J. Use of modern contraception increases when more methods become available Analysis of evidence from 1982 - 2009. Glob Health Sci Pract 2013;1(2):1-10. https://doi.org/10.9745 ghsp-d-13-00010

1. World Health Organization. Hormonal contraception and HIV. 2012. http://www.who.int/reproductivehealth/ topics/family_planning/Hormonal_contraception_and_HIV.pdf (accessed 1 September 2017).

22. World Health Organization. Hormonal Contraceptive Eligibility for Women at High Risk of HIV: Guidance Statement Recommendations Concerning the Use of Hormonal Contraceptive Methods by Women at High Risk of HIV. Geneva: WHO, 2017.

23. http://www.bdlive.co.za/national/health/2014/02/20/new-contraceptive-implant-free-to-women-insa-says-motsoaledi (accessed 5 March 2016).

24. Department of Health. The Contraceptive Implant in South Africa. Pretoria: $\mathrm{DoH}, 2015$

25. Massyn N, Day C, Peer N, Padarath A, Barron P, English R. District Health Barometer 2013/14. Durban: Health Sytems Trust, 2014

26. Massyn N, Peer N, Padarath A, Day C, eds. District Health Barometer 2016/17. Durban: Health System Trust, 2017

27. Ina S. Birth control implant needs a shot in the arm. Mail and Guardian. 22 May 2015. http://women. mg.co.za/birth-control-implant-needs-a-shot-in-the-arm/ (accessed 5 March 2016).

28. ENCA. Checkpoint-Implanon update. https://www.enca.com/media/video/implanon-update? (accessed 5 March 2016).

29. Hardee K, Balogh S, Villinski MT. Three countries' experience with norplant introduction. Health Policy Plan 1997;12(3):199-213. https://doi.org/10.1093/heapol/12.3.199

0. Population Council New York. Jadelle Levonorgestrel Rod Implants: A Summary of Scientific Data an Lessons Learned from Programmatic Experience. New York: PCNY, 2002:1-58.

1. Institute of Medicine. Contraceptive Research, Introduction, and Use: Lessons from Norplant. Washington, DC: National Academies Press, 1998.

2. Simmons R, Hall P, Diaz J, Diaz M, Fajans P, Satia J. The strategic approach to contraceptive introduction. Stud Fam Plann 1997;28(2):79-33. https://doi.org/10.2307/2138111

33. Boonstra H, Duran V, Northington Gamble V, Blumenthal P, Dominguez L, Pies C. The 'boom and bus phenomenon': The hopes, dreams, and broken promises of the contraceptive revolution. Contraception 2000;61(1):9-25. https://doi.org/10.1016/s0010-7824(99)00121-3

4. Solinger R, Nakachi M, eds. Reproductive States: Global Perspectives on the Invention and Implementation of Population Policy. Oxford: Oxford University Press, 2016

5. Hafez ES, van Os WA, eds. Medicated Intrauterine Devices: Physiological and Clinical Aspects. Developments in Obstetrics and Gynaecology. Rotterdam: Springer, 1980:188.

6. Thiery M. Intrauterine contraception: From silver ring to intrauterine contraceptive implant. Eur J Obste Gynecol Reprod Biol 2015;90(2):145-152. https://doi.org/10.1016/s0301-2115(00)00262-

37. Rowlands S, Searle S. Contraceptive implants: Current perspectives. J Contracept 2014;5:73-84. https:// doi.org/10.2147/oajc.s55968

8. Teunissen AM, Grimm BRF. Continuation rates of the subdermal contraceptive Implanon ${ }^{\circ}$ an associated influencing factors. Eur J Contracept Reprod Health Care 2014;19(1):15-21. https://doi.org/ 10.3109/13625187.2013.862231

39. Lakha FGA. Continuation rates of Implanon in the UK: Data from an observational study in a clinical setting. Contraception 2006;74(4):287. https://doi.org/10.1016/j.contraception.2006.05.072

0. Harvey C, Seib C, Lucke J. Continuation of family, rates and reasons for removal among Implanon ${ }^{\circ}$ user accessing two planning clinics in Queensland, Australia. QUT Digit Repos 2009;80(6):527-532. https:// doi.org/10.1016/j.contraception.2009.05.132

41. Kidane A, Asefa T, Asres T, et al. Assessment of implant and IUCD removal in Ethiopia. International Conference on Family Planning Research and Best Practices, Kampala, Uganda, November 2009. http://fpconference.org/2009/media/DIR_169701/15f1ae857ca97193ffff83acffffd524.pd (accessed 5 March 2016)

42. Bertrand JT, Hardee K, Magnani RJ, Angle MA. Access, quality of care and medical barriers in family planning programs. Int Fam Plan Perspect 1995;21(2):64-74. https://doi.org/10.2307/2133525

43. RamaRao S, Lacuesta M, Costello M, Pangolibay B, Jones $\mathrm{H}$. The link between quality of care and contraceptive use. Int Fam Plan Perspect 2003;29(2):76-83. https://doi.org/10.2307/318106

4. Neukom J, Chilambwe J, Mkandawire J, Mbewe RKH. Dedicated providers of long-acting reversible contraception: New approach in Zambia. Contraception 2011;83(5):447-452. https://doi.org/10.1016/j. contraception.2010.08.021

5. Dickerson LM, Diaz VA, Jordon J, et al. Satisfaction, early removal, and side effects associated with longacting reversible contraception. Fam Med 2013;45(10):701-707.

6. Ch ra-Mouli V McCarraher DR, Phillips SJ, Williamson NE, Hainsworth G. Contraception for adolescents in low and middle income countries: Needs, barriers, and access. Reprod Health 2014;11(1):1. https://doi.org/10.1186/1742-4755-11-1

Chandra-Mouli V, Greifinger R, Nwosu A, et al. Invest in adolescents and young people: It pays. A

8. Hubacher D, Olawo A, Manduku C, Kiarie J. Factors associated with uptake of subdermal contraceptive implants in a young Kenyan population. Contraception 2011;84(4):413-417. https://doi.org/10.1016/j. contraception.2011.02.007

McNicholas C, Peipert JF. Long-acting reversible contraception (LARC) for adolescents. Curr Opin Obstet Gynecol 2012;24(5):293-298. https://doi.org/10.1097/gco.0b013e32835686d5

Committee on Adolescents. Contraception for adolescents. Policy statement. Pediatrics 2014;134(4):12441256.

1. Diedrich JT, Klein DA, Peipert JF. Long-acting reversible contraception in adolescents: A systematic revie and meta-analysis. Am J Obstet Gynecol 2017,216(4).e1-e12. hitps.//dat.org/10.1016/).ajog.2016.12.024 O'Neill E, Tang J, Garrett JHD. Characteristics of Kenyan women in a prospective cohort study who continue using subdermal contraceptive implants
https://doi.org/10.1016/j.contraception.2013.11.016

53. Steyn PS, Cordero JP, Gichangi P, et al. Participatory approaches involving community and HCPs in Steyn PS, Cordero JP, Gichangi P, et al. Participatory approaches involving community and HCPs in family planning/contraceptive information and service provision: A scoping review. Reprod Health
2016;13(1):88.

54. Higgins JA. Celebration meets caution: LARC's boons, potential busts, and the benefits of a reproductive justice approach. Contraception 2014;89(4):237-241. https://doi.org/10.1016/j.contrareproductive justice
ception.2014.01.027

55. Ross L. A Primer on Reproductive Justice and Social Change. Berkeley, CA: SisterSong Women of Color Reproductive Health Collective, 2007.

56. World Health Organization. Ensuring Human Rights in the Provision of Contraceptive Information and Services Guidance and Recommendations. Geneva: WHO, 2014

Newman K, Feldman-Jacobs C. Family Planning and Human Rights - What's the Connection and Why is it Important. Policy Brief. Washington DC: Population Reference Bureau, 2015. 
58. Department of Health. Sexual and Reproductive Health and Rights: Reviewing the Evidence Literature Review and Situation Analysis Undertaken to Inform Sexual and Reproductive Health and Rights: Fulfilling our Commitments. 2011 - 2021 and Beyond. Pretoria: DoH, 2011.

59. Department of Health. National Contraception Policy Guidelines Within a Reproductive Health Framework Pretoria: $\mathrm{DoH}, 2001$.

60. Lince-Deroche N, Pleaner M, Harries J, et al. Achieving Universal Access to Sexual and Reproductive Health Services: The Potential and Pitfalls for Contraceptive Services. South African Health Review 2016. Durban: Health Sytems Trust, 2016
61. Patel RC, Morroni C, Scarsi KK, Sripipatana T, Kiarie J, Cohen CR. Concomitant contraceptive implant and efavirenz use in women living with HIV: Perspectives on current evidence and policy implications for family

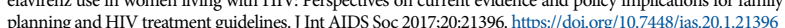
62. Department of Health. National Contraception Clinical Guidelines. Pretoria: DoH, 2012.

Accepted 18 August 2017. 